\title{
A gestão do conhecimento na administração pública municipal em Curitiba com a aplicação do método OKA - Organizational Knowledge Assessment
}

\author{
Carla Cristine Braun \\ Instituto Municipal de Administração Pública de Curitiba (IMAP) \\ Rafael Rodrigo Mueller \\ Universidade do Extremo Sul Catarinense (UNESC)
}

\begin{abstract}
O presente artigo objetiva analisar como a gestão do conhecimento se manifesta na administração pública da Prefeitura Municipal de Curitiba; para tanto, buscou-se a aplicação do método Organizational Knowledge Assessment (OKA), criado pelo Banco Mundial e organizado pela Escola Nacional de Administração Pública (Enap). No que tange aos procedimentos metodológicos, utilizou-se o estudo de caso como instrumento de pesquisa e coleta dos dados. Como resultado, identificaram-se o processo de avaliação organizacional, indicando as similaridades e distinções do desenvolvimento do método de cada área-fim, e a importância de implantar sistematicamente um processo de avaliação aliado ao planejamento da organização pública com estratégias para disseminar, compartilhar e aplicar o conhecimento produzido.
\end{abstract}

Palavras-chave: gestão do conhecimento; administração pública; método OKA — Sysoka; Curitiba.

La gestión del conocimiento en la administración pública del Curitiba com la aplicación del método Organizational Knowledge Assessment (OKA)

Este artículo pretende analizar cómo se manifiesta la gestión del conocimiento en la administración pública de la Ciudad de Curitiba,; por lo tanto, se buscó la aplicación del Método de Evaluación de Conocimiento Organizacional (OKA), creado por el Banco Mundial y organizado por la Escuela Nacional de Administración Pública (Enap). En cuanto a los procedimientos metodológicos, se utilizó el estudio de caso como instrumento de investigación y colección de datos. Como resultado, se identificó el proceso de evaluación de la organización, lo que indica las similitudes y diferencias de desarrollo de métodos de cada área-fin, y la importancia de aplicar sistemáticamente un proceso de evaluación,

DOI: http://dx.doi.org/10.1590/0034-76121620

Artigo recebido em 25 jun. 2013 e aceito em 27 fev. 2014.

Rev. Adm. Pública - Rio de Janeiro 48(4):983-1006, jul./ago. 2014 
junto con la planificación de la organización pública con estrategias para la difusión, el intercambio y la aplicación del conocimiento producido.

Palabras clave: gestión del conocimiento; administración pública; método OKA — Sysoka; Curitiba.

The knowledge management in the municipal public administration in Curitiba with the application of the Organizational Knowledge Assessment (OKA) method

This article aims to analyze how knowledge management is manifested in the public administration of Curitiba's municipal government. To do it, we used the Organizational Knowledge Assessment method (OKA), created by the World Bank and organized by the National School of Public Administration (Enap). Regarding the methodological procedures, the case study was used as a research instrument and data collection. As a result, we identified the process of organizational assessment, indicating the similarities and distinctions of method development of each destined area , and the importance of systematically implementing an evaluation process allied with the planning of the public organization with strategies for disseminating, sharing and applying the produced knowledge

Keywords: knowledge management; public administration; OKA method — Sysoka; Curitiba.

\section{Introdução}

A administração pública tem percorrido um caminho dinâmico, impulsionada por novos desafios, rapidamente assumindo conceitos que até então eram somente utilizados pelo setor privado para realizar a gestão. São criados novos modelos que ampliam a forma de implantar, implementar, monitorar e avaliar ações, projetando as cidades com os temas de planejamento urbano, sustentabilidade, desenvolvimento local, regional, social e outros, estabelecendo indicadores e resultados para a gestão.

Nessa busca constante de aprimorar e conhecer novos modelos de gestão, as cidades se preocupam com a inovação e se projetam para o futuro sem deixar sua história, conservando e contemplando o antigo com o novo, alavancam o desenvolvimento num contínuo inventar e reinventar. A qualidade de vida nas cidades se põe como o desafio maior; e tão importante quanto cuidar e oferecer bens e serviços para os cidadãos é criar condições de trabalho para que os servidores da administração pública aprimorem seus conhecimentos e sejam reconhecidos e valorizados. Impulsionada pela atualização e a modernização, a administração pública cria mecanismos com caráter inovador para gerir e produzir conhecimento.

O Banco Mundial - agência financiadora de ações, projetos e programas que vinculam políticas públicas em prol de países em desenvolvimento, analisando e avaliando práticas, comparando-as aos países desenvolvidos - realiza anualmente relatórios abordando o diagnóstico dessas realidades. No relatório de 1999, pontua duas questões: a defasagem do conhecimento e os problemas da informação (Banco Mundial, 1999).

Em face dessas importantes questões relativas ao conhecimento e à informação, o Instituto do Banco Mundial propôs às organizações o método Organizational Knowledge Assess- 
ment (OKA), criado em 2000. Esse método é apresentado por um software, aplicativo operacional denominado System Organizational Knowledge Assessment (SysOKA), que visa subsidiar um diagnóstico para aferir o grau de maturidade da gestão do conhecimento organizacional. Até 2009, o método havia sido aplicado em 158 organizações nos EUA e Europa; suas principais contribuições refletem a importância do instrumento como subsídios para a construção de um plano estratégico, a partir da sistematização de informações em um diagnóstico, contribuindo para a mudança na cultura organizacional. O método OKA avalia a capacidade e o nível de preparação de uma organização na utilização adequada de seus ativos intelectuais (Fonseca, 2006).

No Brasil, esse método ficou disponível para aplicação a partir de 2009, no Ministério de Planejamento, Orçamento e Gestão (MPOG), que instituiu o Comitê Técnico de Gestão do Conhecimento e Informação Estratégica (CT-GCIE) e o Comitê Executivo do Governo Eletrônico (Cege), a fim de gerenciar a pesquisa e o desenvolvimento da aplicação do referido método. A Escola Nacional de Administração Pública (Enap), também vinculada a esse ministério, executa ações de capacitação, qualificação e formação de técnicos e gestores públicos e solicitou à Universidade Católica de Brasília (UCB) a tradução e a adaptação do método para sua aplicação em organizações do setor público (Brasil, 2012b).

A cidade de Curitiba nas últimas décadas, em sua gestão municipal, tem potencializado essa busca focando resultados na administração pública, a partir da organização interna de processos no modelo de gestão pública para resultados, estabelecidas no Plano de Governo Municipal. Esse modelo gerencial indica ações estratégicas prioritárias que projeta alcançar nos próximos anos com acompanhamento e monitoramento quadrimestral e projeção avaliativa anual. Para tal, é necessário não apenas gerir estruturas com recursos materiais, físicos, humanos e outros, mas também desenvolver um modelo de gestão, onde as competências operacionais e gerenciais sejam desenvolvidas estrategicamente num sistema de educação corporativa do setor público (Giacomini, 2009).

Dentre as estratégias da administração municipal, destacam-se políticas internas de valorização do corpo funcional pela gestão de competências e gestão do conhecimento, desenvolvidas pelo Instituto Municipal de Administração Pública (Imap), que é um órgão de administração pública indireta da Prefeitura. Neste âmbito, as ações de responsabilidade da Escola de Administração Pública (EAP) orientam para a formação, o aprimoramento, a capacitação em modalidades presencial e a distância, por meio de um Plano de Desenvolvimento de Competências. Assim como a promoção de ações para identificar práticas de servidores e de equipes, essas ações integram a Semana do Conhecimento "Se a PMC soubesse o que a PMC sabe", que tem por finalidade divulgar, compartilhar e disseminar o conhecimento para os demais servidores, propiciando novos conhecimentos.

A gestão do conhecimento na Prefeitura se configura por meio de processos de trabalho que norteiam produtos; estes são organizados em planos de ação, e resultam em práticas com diretrizes estabelecidas, relevâncias estratégicas e impactos previstos, cumprindo metas qualitativas e quantitativas pelos articuladores da gestão do conhecimento na Prefeitura em sua execução e avaliação. Observou-se uma lacuna no tocante ao processo de avaliação das 
ações da gestão do conhecimento, enquanto diagnóstico e resultados, pois os produtos e as práticas gerados acabam sendo diluídos e incorporados aos resultados previstos, em eventos de compartilhamento, registro de informações, do conhecimento elaborado e produzido em várias áreas e setores da Prefeitura. Em 2010, o Imap em parceria com a Enap propôs capacitar técnicos da gestão do conhecimento na Prefeitura de Curitiba. O curso intitulado "Diagnosticando a gestão do conhecimento" ocorreu, mas o método foi aplicado apenas como um exercício sem a prática institucional.

Considerando esse contexto, buscou-se em nossa pesquisa analisar como a gestão do conhecimento se manifesta no setor público municipal, a partir de um estudo de caso da Prefeitura de Curitiba amparado na aplicação do método OKA e o software SysOKA. Nesse sentido, inicialmente foram apresentados os referenciais teóricos que subsidiam a discussão sobre a administração pública, abordando a gestão por resultados e a gestão do conhecimento. Em seguida delineou-se a metodologia de aplicação do referido método em áreas selecionadas da Prefeitura assim como a análise dos dados obtidos, encerrando com as considerações finais.

\section{Marco referencial teórico}

\subsection{Administração Pública}

O Estado se afirma como um ente representativo da sociedade civil para os interesses comuns, visa garantir e regular a forma de julgar, executar para reconhecer e legislar para o bem maior, balizando direitos em prol de um interesse coletivo. Com intuito de um projeto comum que favorece aos indivíduos o ingresso ao sistema político, este age por associação de interesses comuns, passando de ideológico para racional (Bobbio e Bovero, 1994).

O papel da administração pública é atuar como eixo transmissor entre o Estado e a sociedade, seguindo princípios de racionalidade e eficiência, contribuindo para o fortalecimento institucional e a modernização administrativa desses serviços, focado em responsabilidades desde a formulação de políticas públicas até sua implantação, implementação e execução administrativa (Wilson, 2005).

Segundo Waldo (1971:6), a "administração pública é a arte e a ciência das gerências aplicadas aos negócios do Estado", reforçando a finalidade do Estado que é o desenvolvimento de políticas públicas para o bem comum, acrescentando que também "é a organização e a gerência de homens e materiais para a consecução dos propósitos de um governo". Assim, a administração pública é a gestão de serviços e de bens entregues à comunidade, de forma qualitativa para o bem comum segundo a orientação do direito, leis, normas e outros; e da moral.

A administração pública em seu processo de modernização visa realizar sua função social, de forma profissional, aperfeiçoando seu sistema de controle social, melhorando a qualidade dos serviços públicos oferecidos aos cidadãos e buscando modelos de gestão com referência ao cumprimento de objetivos, valorizando o servidor público, visando melhores re- 
sultados, exigindo da organização e, consequentemente, de seus servidores maior flexibilidade, criatividade e compromisso. Assim, a administração pública terá como meta o olhar para o resultado enquanto uma devolutiva de sua real função, e também o olhar para o interno, focando o aperfeiçoamento de seu capital humano, com investimento em processos de pesquisa, seleção, treinamento e formação de seus gestores. Segundo Matias-Pereira (2010:5),

mesmo que a Administração Pública se inspire no modelo de gestão privada, devemos ressaltar que nunca se deve perder a perspectiva de que o setor privado visa ao lucro, enquanto a Administração Pública busca realizar sua função social. Essa função social deve ser alcançada com maior qualidade e eficiência possível na sua prestação de serviços.

No setor público o lucro se traveste no investimento para conquista de uma eficiência na qualidade dos serviços, utilizando ferramentas, modelos de gestão e outros para ampliar sua capacidade de governo. Prestes Motta (1997:15) considera que

(...) governar significa tomar decisões sobre alternativas de ação para a sociedade. Tais alternativas têm como base, em princípio, o interesse público expressado coletivamente, de acordo com um processo administrativo onde demandas e apoios são convertidos em normas, produtos e serviços.

Assim, ineficiente, ineficaz e não efetivo é tratar a administração pública como uma administração privada. Enquanto conceitos de administração, estes podem ser utilizados para o planejamento e a gestão na administração pública, não focada nos interesses de competição com o mercado e com demais entes de instâncias públicas. Como também competir para o atingimento de metas, distanciando-se de sua função social e do papel público de elencar prioridades de governo, focando unicamente a gestão voltada ao interesse de conquistar índices valorativos que registrem resultados quantitativos.

\subsection{Gestão por resultados na administração pública}

Para Matias-Pereira (2010:7),

os governantes buscam, na atualidade, desenvolver ações e medidas para melhorar o desempenho da Administração Pública (...), destacam-se aquelas orientadas para a priorização na gestão por resultados, monitoramento de prioridades de governo e programas estratégicos, e contratualização de resultados.

Para que a gestão pública tenha efetividade, o primeiro passo de um planejamento estratégico é o diagnóstico, a identificação de problemas, traduzidos em demandas e necessidades, cenários atuais e construção de cenários futuros. A estratégia para o setor público é 
alinhar os objetivos da organização e as demandas da população. O planejamento deve estar em sintonia com demais setores e áreas envolvidas para o alcance dos resultados propostos, constar a gestão e o processo de avaliação e controle, completando um ciclo, visando garantir a qualidade e a transparência de suas ações realizadas.

A gestão por resultados visa a fortalecer a ação dos organismos públicos para melhorar os resultados em benefício dos cidadãos e da sociedade. O referido termo deriva da lógica da administração por objetivos (Drucker, 1999). Está pautada numa lógica de eficácia e eficiência, com a otimização do uso dos recursos públicos, o processo de produção de bens e serviços públicos, melhorar o desempenho dos dirigentes e servidores públicos, tornar efetivos os mecanismos governamentais, sendo transparente, equitativo e controlável (Serra, 2008).

No setor público as bases estão apoiadas na legalidade, tanto da responsabilidade na gestão fiscal dos recursos públicos e prestação de contas, quanto da ordem devolutiva para a população. O planejamento apresenta-se como um conjunto de ações interligadas, envolve uma série de atividades, é contínuo, permanente e sistemático, podendo ser um processo de tomada de decisão, uma atividade orientada para o alcance dos objetivos e, consequentemente, resultados para a sociedade.

Na administração pública municipal a sociedade está mais próxima participando, tanto na utilização dos serviços quanto da discussão nos processos democráticos que definem e orientam a política pública. Para tal, a gestão deve reordenar e reorganizar sua plataforma com parcerias com instituições, atores sociais, entes federativos e outros envolvidos no processo. O planejamento municipal deve ter caráter integral e integrado, explorando limites do plano diretor municipal (Fidelis e Rezende, 2008). Deve conter essencialmente objetivos, metas, prazos que contemplem estratégias para sua implementação e alinhamento em face dos resultados definidos.

O Banco Mundial, a partir do ano 2000, "elabora um sistema dinâmico de gestão do conhecimento, capaz de destilar os conhecimentos e torná-los disponíveis para serem adaptados e utilizados em outras áreas" (Banco Mundial, 1999:7). Por conseguinte, a criação de processos que implementam a valorização e a disseminação dos conhecimentos técnicos pode auxiliar o desenvolvimento em outros países, levando-se em conta aspectos da cultura local e regional, gerando e produzindo novos conhecimentos.

Assim, a gestão do conhecimento é utilizada como um meio estratégico, processos organizados que reúnem a memória organizacional da administração pública, no sentido de disponibilizá-la para o aprendizado interno e para o desenvolvimento institucional.

\subsection{Gestão do conhecimento}

O conhecimento é resultado de uma ação, um produto em movimento contínuo, como um ciclo que se reinicia no momento de apropriação da informação, pela interação da pessoa com a informação. O que diferencia a informação do conhecimento é que o fator humano interage sobre a informação, potencializa e gera o conhecimento por meio da interpretação e do de- 
senvolvimento de habilidades e competências humanas à informação, pois o conhecimento é uma produção, uma interpretação elaborada da informação recebida, que acrescenta e agrega um novo valor à informação.

Segundo Drucker (1999:32), informações "são dados interpretados, dotados de relevância e propósito". Os dados, para Davenport e Prusak (1998:2), "são um conjunto de fatos distintos e objetivos, relativos a eventos"; nesse caso, eles são a base para as informações, que são dados com valor agregado, e que agrupadas geram um significado, qualidade ou representatividade do que é - vincula interpretação e entendimento, tem um porquê. "O conhecimento é a informação mais valiosa, mais difícil de gerenciar. É valiosa precisamente porque alguém deu à informação um contexto, um significado, uma interpretação (...) acrescentou a ele sua própria sabedoria" (Davenport e Prusak, 1998:19). O conhecimento é subjetivo e passa a ser informação a partir do momento em que ele é transmitido, sistematizado, passado a outro que se apropria gerando um novo conhecimento.

Polanyi (1996:82) identifica o conhecimento numa dimensão tácita como "espontâneo, intuitivo, experimental, conhecimento do cotidiano"; sendo algo subjetivo e difícil de ser mensurado e descrito, esse conhecimento é interno, do sujeito. Em seu livro The tacit dimension (1966) apresenta o conhecimento tácito de duas formas: o distal se refere ao conhecimento específico dotado de uso de uma técnica natural a partir de um movimento internalizado, de uma atitude inconsciente já capturada; e o proximal quando a consciência se apropria da técnica.

A forma de externalizar esse saber, até então subjetivo, ocorre a partir da sua relação e capacidade de se comunicar, se utilizando de ferramentas e técnicas que podem ser aprendidas e treinadas para aprimorar esse exercício em seu cotidiano. Essa comunicação pode ocorrer de modos diversos, por meio de linguagens múltiplas, como: a fala, os gestos, os símbolos, a representação gráfica. A escrita é uma forma de sistematizar esse saber, formalizar o conhecimento adquirido em materialidade, em informações e processos descritos. Esse conhecimento é chamado de explícito, que tem origem no latim = explicitus e tem por significado o termo: explicar, declarar.

Para Nonaka e Takeuchi (1995:64), "tanto a informação quanto o conhecimento são específicos ao contexto e relacionais na medida em que dependem da situação e são criados de forma dinâmica na interação social entre as pessoas". Então, propiciar um bom ambiente de nada adianta se as pessoas não estiverem motivadas; assim, o desafio é criar condições para que as pessoas possam desenvolver habilidades e competências, num contexto organizacional para se obter o conhecimento criativo. Para Batista e colaboradores (2005), os processos empreendidos na busca das informações, tanto a coleta, a organização e o acesso às fontes, são fundamentais para a atuação e a prática profissional, transformando as informações na organização em conhecimento.

A informação é a base da gestão e do planejamento da administração pública; a falta de acesso às informações e a falta de veracidade podem distorcer ou ignorar fontes para a tomada de decisão. Matias-Pereira (2010:62) sintetiza "que a eficiência está relacionada ao método com o qual realizamos as ações pretendidas, eficácia diz respeito ao resultado final da ação e efetividade corresponde ao grau de qualidade do resultado obtido". 
A informação é considerada uma força vital, propulsora que alavanca e que gera a vantagem competitiva entre as organizações, "serve para verificar a qualidade, acompanhar o desempenho e regulamentar as transações, proporcionando a base de um desenvolvimento" (Banco Mundial, 1999:08), essencialmente para a ação pública. Assim, se faz necessário realizar a gestão da informação para que possa ser utilizada estrategicamente na organização, como fora dela também, numa relação de troca e de poder.

De Long, Davenport e Beers (1997:23) consideram que nas organizações ocorre um limite muito tênue entre a gestão da informação e a gestão do conhecimento, dificultando a percepção entre suas fronteiras. Nesse âmbito da gestão, Drucker (1999) apresenta o conceito de gestão do conhecimento como uma estratégia que coloca a organização em posição de vantagem competitiva com "a capacidade de gerenciar, descobrir, mapear, classificar, captar, distribuir, criar, multiplicar e reter conhecimento com eficiência, eficácia e efetividade". E por meio da gestão, fortalecendo o conhecimento como recurso organizacional para atingir resultados.

Assim, a gestão do conhecimento possui, segundo Angeloni (2008:02), "um conjunto de processos que governa a aquisição, a criação, o compartilhamento, o armazenamento e a utilização de conhecimento no âmbito das organizações”. Um conjunto de processos sistemáticos que organizam o conhecimento que se encontra nos ativos intangíveis da organização ou no referencial de capital intelectual da mesma. Sveiby (1998) refere-se à arte de criar valor a partir dos ativos intangíveis, pois, com base em Santos e colaboradores (2001:32), a gestão do conhecimento abrange um "processo sistemático de identificação, criação, renovação e aplicação dos conhecimentos que são estratégicos na vida de uma organização".

Na visão de Peluffo e Catalan Contreras (2002:32), a gestão do conhecimento

é uma disciplina emergente que tem como objetivo gerar, compartilhar e utilizar o conhecimento tácito (know how) e explícito (formal) existente em um determinado espaço, para dar respostas às necessidades dos indivíduos e das comunidades em seu desenvolvimento.

Segundo Nonaka e Takeuchi (1995:47), a gestão do conhecimento deverá cultivar uma "abordagem de integrar, identificar, gerir e partilhar toda a informação da empresa, seja ela, base de dados, políticas, procedimentos, cultura, processos e assim como todas as experiências pessoais dos colaboradores". Consideram De Long, Davenport e Beers (1997) que a disseminação do conhecimento passa a ser um desafio, pois a cultura organizacional influencia muito as pessoas na organização, e estas acabam por não aderirem, por receios, medos e demais circunstâncias expositivas. Contudo, os processos de trabalho vinculados à gestão do conhecimento permeiam o fato fundamental de que as organizações estabelecem formas de procedimentar o controle, o passo a passo para delimitar o que cabe à gestão do conhecimento.

Processos bem delineados culminam na excelência do desempenho, mantêm o foco em tarefas que agregam valor à organização, avaliando o impacto, o desempenho e a estratégia da organização. Também estão direcionados ao planejamento, identificam os passos, etapas, 
fases; estabelecem objetivos, metas, prazos; definem responsáveis; norteiam, monitoram e avaliam resultados; implementam indicadores que visam a assegurar a efetividade e a eficiência. Os processos fazem parte de um ciclo com início, meio e fim, onde o gerenciamento possui o controle organizacional a partir de seus processos de trabalho, buscando a melhoria da cadeia de relacionamentos, otimizando recursos e utilizando conceitos de mínimos recursos e máximo resultado (Terra, 2005).

O ambiente organizacional é propício para o desenvolvimento de habilidades e competências geradas estrategicamente pela formação e educação permanente e continuada, pois o aprendizado se dá pelo resultado tanto das interações quanto pelo conteúdo apropriado. A comunidade de prática ou communities of practice é um conceito de Etienne Wenger, culmina em um espaço de compartilhamento de ideias e de conhecimento em rede, visa a ampliar e desenvolver aprendizados, estes a partir de temas e interesse comum (Terra, 2005).

A gestão do conhecimento vem se apropriando de várias ferramentas, principalmente das tecnológicas, para maior e melhor qualidade dos produtos e práticas a fim de alcançar as pessoas e as equipes, objetivando disseminar o conhecimento produzido pela organização. Destarte, tendo por base o construto teórico sobre a gestão do conhecimento aqui indicado na administração pública e sua relação com a realidade empírica, apresentamos a pesquisa desenvolvida na Prefeitura Municipal de Curitiba a partir da aplicação do Método OKA.

\section{Metodologia}

Definiu-se pela aplicação do método OKA no intuito de identificar fragilidades e desafios perante a necessidade de se obter um diagnóstico da gestão do conhecimento, resultado da utilização do software SysOKA do Banco Mundial. Esse sistema emite um relatório com a identificação do grau de maturidade e a impressão no formato de gráfico a partir da leitura das 199 questões propostas, com perguntas e respostas orientadas em três elementos agrupados de análise: pessoas, processos e sistemas. Esses elementos abordam 14 dimensões do conhecimento, assim distribuídas:

v Pessoas: Incentivos Culturais; Criação e Identificação do Conhecimento; Compartilhamento de Conhecimento; Comunidades de Prática e Times de Conhecimento; Conhecimento e Aprendizagem.

v Processos: Liderança e Estratégia; Fluxos de Conhecimento; Operacionalização do Conhecimento; Alinhamento; e Métricas e Monitoramento.

v Sistemas: Tecnologia; Conteúdo do Conhecimento; Programa de Gestão do Conhecimento; e Infraestrutura e Acesso ao Conhecimento (Brasil, 2012a).

Desenvolveu-se o estudo de caso realizado na Prefeitura Municipal de Curitiba em 10 áreas-fins selecionadas que representam 70\% do corpo funcional, por meio da aplicação do 
método OKA, que é composto por quatro etapas: Inicial, Preparatória, Operacional e Final; subdivididas em 12 fases, conforme figura 1.

\section{Figura 1}

Diagrama de aplicação do método Organization Knowledge Assessment (OKA)

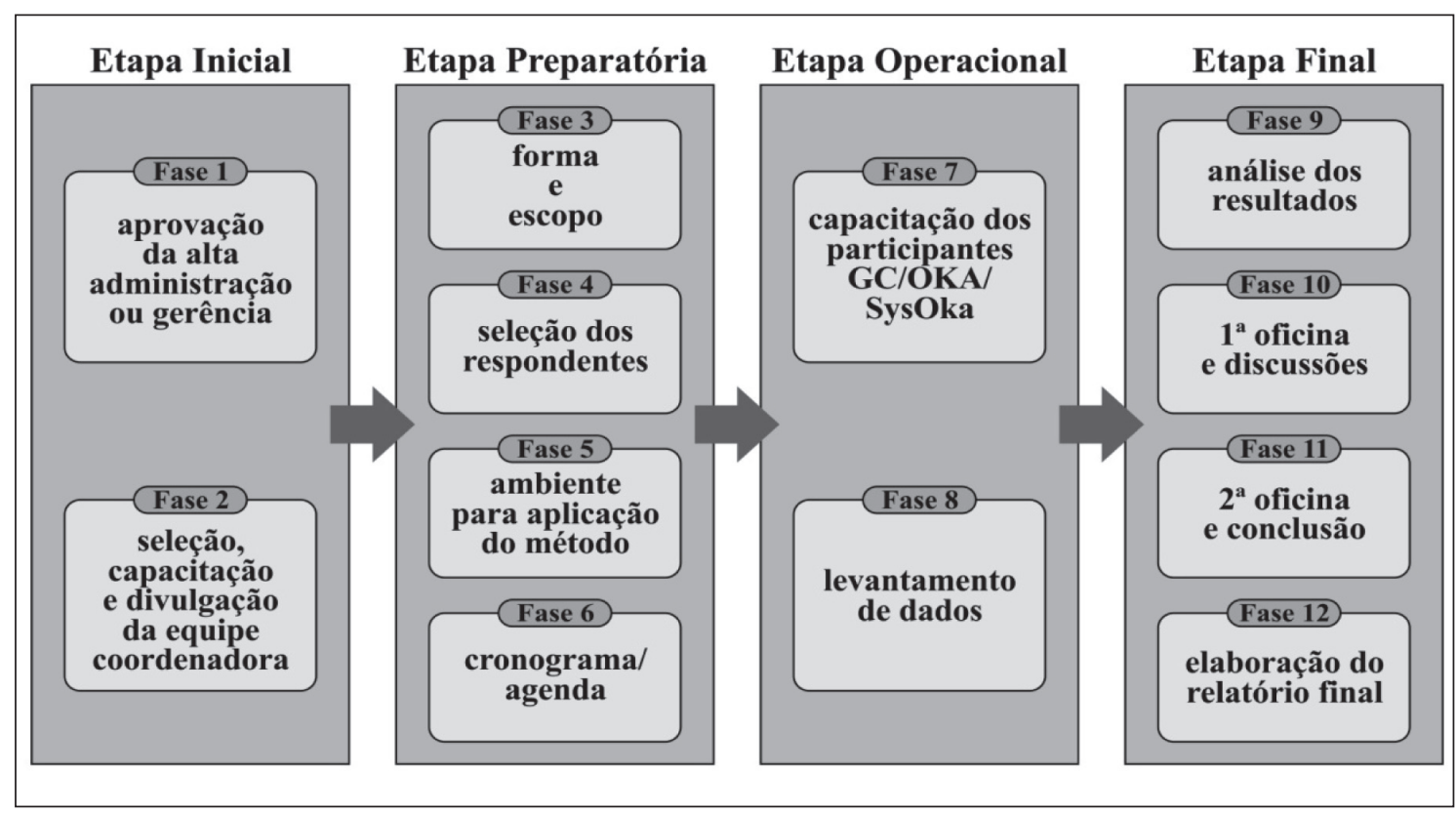

Fonte: Enap (Brasil, 2012a).

Discorre-se sobre a aplicação do método OKA em suas seguintes etapas.

\section{Etapa inicial: fases 1 e 2}

Validação junto às instâncias estratégicas da organização e a definição de área meio como coordenadora desse estudo, o Instituto Municipal de Administração Pública. Foram selecionadas 10 áreas: Abastecimento, Assistência Social, Cultura, Educação, Esporte e Lazer, Habitação, Segurança, Trabalho, Turismo e Urbanismo; estas vinculadas às secretarias e órgãos que executam políticas públicas junto aos cidadãos da cidade de Curitiba.

\section{Etapa preparatória: fases 3 a 5}

Apresentação da proposta e forma de operacionalização do método OKA, com as áreas selecionadas. Foram indicados "articuladores da gestão do conhecimento": servidores públicos, 
técnicos com formação superior em diferentes áreas que ocupam cargos de gerenciamento, coordenações e assessorias junto às secretarias e aos órgãos.

\section{Etapa operacional: fases 6 e 7}

Estabeleceu-se o período de cinco meses para a apropriação do método, elaboração de documento com orientações, discussão, preenchimento e validação interna em cada secretaria e órgãos vinculados; como também a utilização do sistema, resultado e conclusão. Iniciou-se com a apostila da Enap (Curitiba, 2012), que apresenta o alinhamento conceitual sobre o método e o questionário contendo as 199 questões.

\section{Etapa final: fases 8 a 12}

Cada articulador vinculado à área selecionada é responsável por acionar os demais setores que complementariam as informações solicitadas para a aplicação do método no sistema. Com o retorno dos dados coletados, solicitamos o download do sistema aplicativo do SysOka para o preenchimento eletrônico. Ocorreu a consolidação dos dados, a emissão de tabela com o grau de maturidade e o gráfico modelo spider. A análise realizada em conjunto com o grupo

e, posteriormente, os demais setores envolvidos no nível estratégico da organização foram estimulados a realizarem apresentação e discussões internas com as equipes nas referidas secretarias e órgãos de vinculação.

Assim, a aplicação do método OKA foi realizada, compilando informações em documento único, disponibilizado aos gestores das áreas envolvidas, como também ao Instituto Municipal de Administração Pública, contemplando de forma descritiva todas as etapas, fases e resultados coletados, culminando no diagnóstico.

\section{Análise dos resultados}

A seguir apresenta-se o resultado das análises do diagnóstico da gestão do conhecimento com base no Método OKA e os respectivos elementos:

- Elemento pessoas: apresenta cinco dimensões do conhecimento: a) incentivos culturais; b) comunidade de prática e times do conhecimento; c) compartilhamento do conhecimento; d) criação e identificação do conhecimento; e) conhecimento e aprendizagem, apresentados na tabela 1. 
Tabela 1

Grau de maturidade no elemento pessoas

\begin{tabular}{|lccccc|}
\hline $\begin{array}{c}\text { Áreas de Atuação } \\
\text { da PMC }\end{array}$ & $\begin{array}{c}\text { Incentivos } \\
\text { Culturais }\end{array}$ & $\begin{array}{c}\text { Comunidade de } \\
\text { Prática e Times } \\
\text { do Conhecimento }\end{array}$ & $\begin{array}{c}\text { Compartilha- } \\
\text { mento do } \\
\text { Conhecimento }\end{array}$ & $\begin{array}{c}\text { Criação e } \\
\text { Identificação do } \\
\text { Conhecimento }\end{array}$ & $\begin{array}{c}\text { Conhecimento e } \\
\text { Aprendizagem }\end{array}$ \\
\hline Assistência Social & 25,1 & 35,4 & 30,1 & 41,2 & 56,3 \\
Cultura & 22,6 & 7,2 & 26,1 & 29,3 & 29,2 \\
Educação & 32,4 & 43,9 & 29,3 & 43,8 & 37 \\
Esporte e Lazer & 24,8 & 27,7 & 24,5 & 36 & 44 \\
Habitação & 21,3 & 6,1 & 15,8 & 14,2 & 27,8 \\
Abastecimento & 24,6 & 26,8 & 18,3 & 40,1 & 43,3 \\
Segurança & 18,7 & 3,9 & 17,6 & 16,5 & 34,9 \\
Turismo & 20 & 25,8 & 13,8 & 21,6 & 27,1 \\
Trabalho & 15,5 & 25,3 & 13,3 & 20,3 & 50,7 \\
Urbanismo & 27,5 & 21,1 & 18,3 & 27,6 & 44 \\
Média das 10 áreas & 23,25 & 22,32 & 20,71 & 29,06 & 33,16 \\
\hline
\end{tabular}

Fonte: Elaborado pelos autores (2013).

A dimensão do conhecimento "incentivos culturais" remete-se às reflexões de atenção à cultura organizacional, possibilitando a leitura sobre o compromisso da organização com a gestão das pessoas, mecanismo de cooperação, recepção de ideias inovadoras e de risco, plano de carreira, ascensão profissional, mudança de área, sistemas de benefícios, recompensas e outros. Referindo-se às crenças, atitudes e comportamentos voltados ao alcance dos objetivos e metas estratégicas da organização. Identifica-se que a média das 10 áreas totalizou o grau de maturidade 23,25 , permanecendo as áreas de segurança, turismo e trabalho pouco abaixo dessa média com o grau médio considerado pela aferição. As demais áreas enquadram-se $60 \%$ no grau alto, e a área da educação com o grau muito alto. Observa-se que os incentivos culturais na organização ocorrem de forma variada em cada área, e que a forma de executar políticas internas e realizar a gestão de pessoas não ocorre de forma equitativa.

A dimensão "comunidades de prática e times do conhecimento" refere-se aos grupos formados na organização, pessoas e equipes mobilizadas para empreender ações que impulsionem o cumprimento de objetivos, por meio de grupos de estudo formais e informais, pesquisa e avaliação, criando espaço de discussão e de produção do conhecimento para ampliar a visão, resolver dificuldades e desafios na organização. Reflete desafios a serem implementados pelo diálogo e valorização do grupo de trabalho no que tange não só à comunicação entre pares, mas quanto à oficialização e à validação institucional desses grupos. Identifica-se que pouco se estimula o fortalecimento de grupos para a aprendizagem, sendo esse ponto fundamental para a produção do conhecimento, evidenciando que cada área lida de forma diferente com seu grupo, apresentando uma disparidade entre essas áreas com a concentração 
de três áreas que demonstram a fragilidade em relação a esse item; a cultura, a habitação e a segurança com grau de maturidade baixo. Esse resultado é muito distante da média das 10 áreas, que é de 22,32; com exceção das três áreas citadas e a área de urbanismo com o grau alto, as demais áreas obtiveram grau acima dessa média, culminando em $60 \%$ acima da média das áreas. Em destaque as áreas da assistência social e da educação que obtiveram o grau de maturidade muito alto, pois pontuaram acima de 35 .

A dimensão "compartilhamento do conhecimento" denota qual o tipo de estrutura a organização possui e disponibiliza para a difusão do conhecimento, destaca a importância desse item, que consiste na capacidade de disseminar, trocar os conhecimentos para que a organização atinja seus objetivos e metas. Faz refletir sobre como a gestão pública lida com a comunicação: que estratégias são criadas e desenvolvidas para que ocorra a disseminação e a fluidez deste conhecimento, bem como sua relação com os itens pontuados anteriormente sobre os incentivos às pessoas, a formalização e o apoio às comunidades que potencializam a produção do conhecimento. Em mais de $60 \%$ das áreas pesquisadas ocorre a necessidade expressa de valorizar o potencial dos servidores com a troca e a partilha do conhecimento na organização, refletindo fragilidade em relação à cultura e à visão estratégica organizacional. Pontuando-se a média de 20,71 para o grau de maturidade, considerando o grau médio, elencamos que, das 10 áreas pesquisadas, apenas quatro áreas (assistência social, cultura, educação, e esporte e lazer) contemplam alto grau de maturidade nesse item. Já as demais áreas permaneceram no grau médio.

A dimensão "identificação e criação do conhecimento" é a habilidade que a organização possui para identificar o capital humano gerador de conhecimento e quais esforços, investimentos e otimização de recursos são necessários para criar novos conhecimentos, ou para capturar, reter, gerar informações que culminam na produção de conhecimento. $\mathrm{O}$ ambiente de trabalho na organização acaba por ser uma consequência sobre incentivos, espaços criados, possibilidades que são disponibilizadas para que pessoas e grupos se apropriem de reflexão, discussão, estudo, pesquisa e informações para a produção do conhecimento. Tal dimensão refere-se à apropriação a partir de técnicas, instrumentos que visem o aprimoramento da aprendizagem por meio de treinamentos, capacitações realizadas pela organização em seus processos de trabalho e como se utiliza, como se aplica o conhecimento, o know-how, incorporando as informações produzidas às atividades realizadas na organização. Observa-se que as 10 áreas atingiram uma média de 29,06, apresentando alto e muito alto grau de maturidade, tendo em vista também que quatro áreas (assistência social, educação, esporte e lazer e abastecimento) em destaque demonstram grau muito alto, acima de 36. Enquanto nas áreas de habitação, segurança e trabalho estrategicamente se faz necessário priorizar a criação e a identificação do conhecimento para potencializar a produção deste na organização.

Em destaque, o item "conhecimento e aprendizagem" reforça o papel fundamental que um órgão de formação e aperfeiçoamento tem em instâncias de natureza meio, qual seja, por atribuição, desenvolver políticas de incentivos e de valorização funcional para que o desen- 
volvimento institucional e com a preocupação contínua em capacitar e formar profissionais no setor público. A média de 33,16 reflete o compromisso que a organização tem com o conhecimento e a aprendizagem nas 10 áreas; assim, denotam seu grau de maturidade, apresentado em 30\% das áreas com grau alto e em 70\% com grau muito alto. Ocorre visualmente o reflexo da busca por desenvolver metodologias e aplicá-las, mostrando um equilíbrio desse item, pois os dados expressos orientam a diretriz de formação e aperfeiçoamento na área de desenvolvimento de competências dos servidores públicos focados nas áreas de interesse da organização.

Fechando a análise do "elemento pessoas", cada uma das cinco dimensões do conhecimento permeia as estratégias que a organização define e opera para desenvolver as capacidades e habilidades das pessoas que produzem o conhecimento na organização. Associa-se a não convergência das diretrizes da organização com o resultado, quando de pronto observa-se no gráfico 1 a sobreposição das dimensões do conhecimento, focando o elemento pessoas, que ainda em sua grande concentração permanece no grau de maturidade até 30 , considerado alto, contemplando $70 \%$ dos resultados apresentados.

Gráfico 1

\section{Grau de maturidade no elemento pessoas}

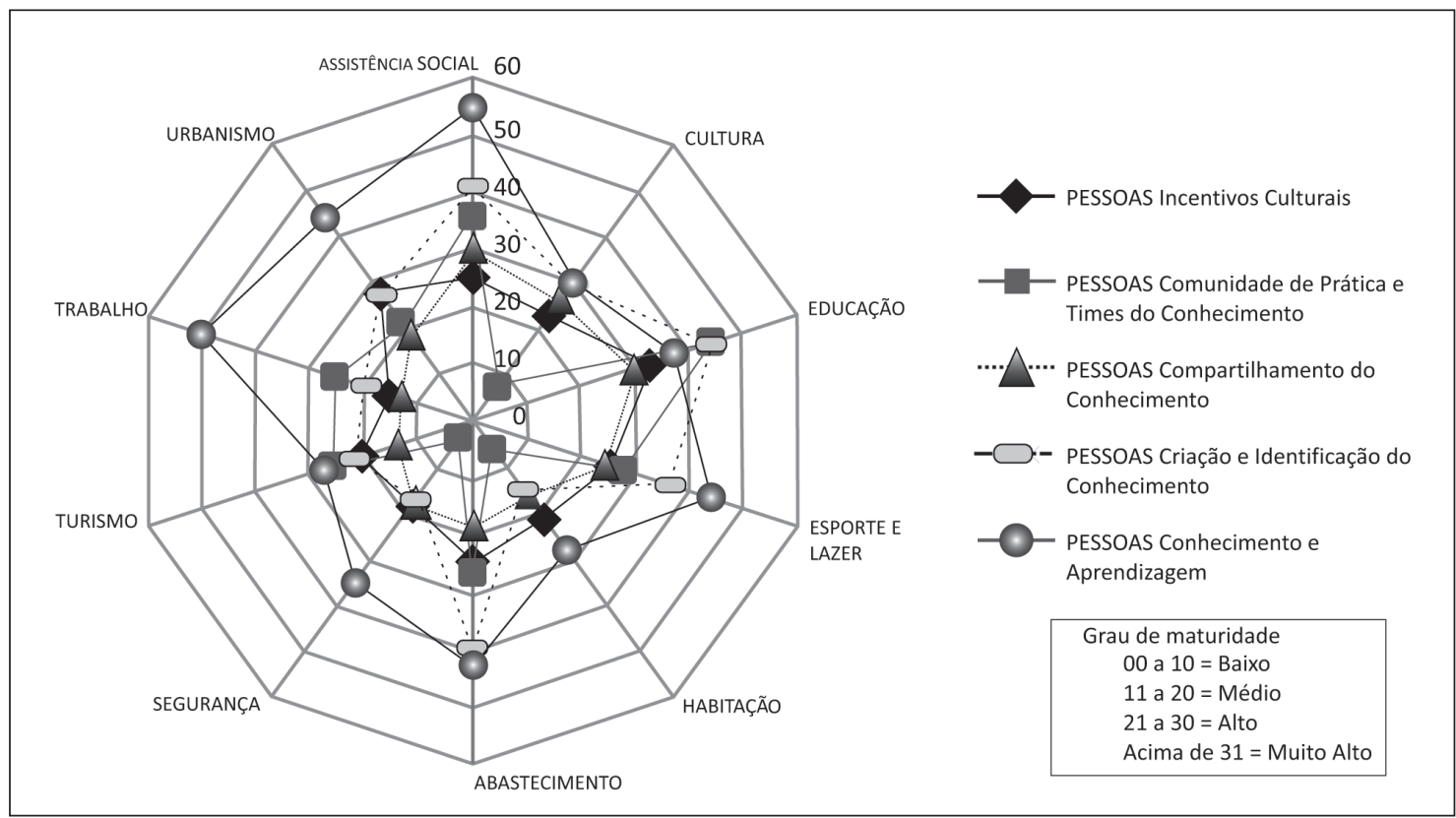

Fonte: Elaborado pelos autores (2013).

— Elemento processos: indica cinco dimensões pautadas em: a) liderança e estratégia; b) fluxo do conhecimento; c) operacionalização do conhecimento; d) alinhamento; e) métricas e monitoramento, a seguir na tabela 2. 
Tabela 2

Grau de maturidade no elemento processos

\begin{tabular}{|lccccc|}
\hline $\begin{array}{c}\text { Áreas de Atuação } \\
\text { da PMC }\end{array}$ & $\begin{array}{c}\text { Liderança e } \\
\text { Estratégia }\end{array}$ & $\begin{array}{c}\text { Fluxo do } \\
\text { Conhecimento }\end{array}$ & $\begin{array}{c}\text { Operacionalização do } \\
\text { Conhecimento }\end{array}$ & Alinhamento & $\begin{array}{c}\text { Métricas e } \\
\text { Monitoramento }\end{array}$ \\
\hline Assistência Social & 44,7 & 37,3 & 33,6 & 28,3 & 41,9 \\
Cultura & 23,2 & 26,9 & 29,1 & 22,2 & 17,8 \\
Educação & 35,8 & 33,8 & 32,5 & 15,7 & 14,8 \\
Esporte e Lazer & 35 & 35,9 & 28,8 & 28,3 & 25,7 \\
Habitação & 20,5 & 18,5 & 22,2 & 8 & 15,2 \\
Abastecimento & 37,1 & 21,6 & 31,3 & 26,1 & 31,4 \\
Segurança & 34,7 & 11,1 & 21,1 & 12,9 & 9 \\
Turismo & 23,2 & 13,1 & 18,8 & 18,8 & 14,8 \\
Trabalho & 38,4 & 16,8 & 30,5 & 22 & 9,5 \\
Urbanismo & 43,9 & 23,5 & 38,2 & 21,4 & 26,7 \\
Média das 10 áreas & 33,65 & 23,85 & 25,48 & 20,37 & 20,68 \\
\hline
\end{tabular}

Fonte: Elaborado pelos autores (2013).

Na dimensão "liderança e estratégia" consideram-se os valores corporativos agregados à organização tendo por foco a gestão realizada pelos líderes e gerentes associados aos processos estratégicos prioritários em relação à flexibilidade no trato com as mudanças, novas ideias e dinâmicas que incorporam o processo de trabalho. Os processos surpreendem por estarem bem definidos e estrategicamente voltados aos objetivos e metas da organização, pois todas as áreas se encontram acima do grau 20 de maturidade, com uma média entre as áreas de 33,65, considerados por essa aferição um grau de maturidade muito alto na organização. Apresentam uma consistência diante das definições de liderança, enquanto clareza nos processos desempenhados pelos líderes com foco nas diretrizes da organização. Aqui ocorre um diálogo alinhado entre a formação dos líderes com as estratégias do modelo de gestão, que atribui ações conjuntas das áreas meio de planejamento e formação.

A dimensão "fluxo do conhecimento" refere-se à fluência dos processos de trabalho organizados, sua efetividade na captura e retenção desse conhecimento, no armazenamento, na transformação, no compartilhamento voltado aos aspectos de como gerar procedimentos para a organização atingir seus objetivos e metas. Indica que $40 \%$ das áreas refletem grau de maturidade até 20 , considerado médio, sendo importante desenvolver com clareza e objetividade os procedimentos gerados no fluxo do conhecimento, para ampliar a capacidade da organização em criar condições de registro sistemático. E 30\% correspondente ao grau de maturidade muito alto, ressaltando as ações que as áreas da assistência social, educação e esporte e lazer vêm realizando na sua sistematização de processos com a criação de protocolos, manuais e demais documentos que registrem procedimentos e normas na organização. As áreas da cul- 
tura, abastecimento e urbanismo, com o grau de maturidade alto, também desenvolvem essa ação com bom desempenho quanto ao fluxo do conhecimento.

A dimensão "operacionalização do conhecimento" registra o potencial de transformar em um produto o conhecimento gerado, objetivando sua utilização apoiada nos resultados, estabelecendo processos organizacionais integrados, possibilitando abertura de novos caminhos, ideias, mudando e revendo rotinas de práticas culturais e estratégicas já estabelecidas. A operacionalização das ações apresenta uma média de 25,48 de grau de maturidade, ficando abaixo dessa média apenas as áreas do turismo, habitação e segurança. Identifica-se também que acima do grau 31 é que se aplica o grau de maturidade muito alto, onde 40\% das áreas que executam as ações por processos operacionais, visando o conhecimento, empreendem de forma sistemática e organizada suas atribuições na organização.

A dimensão "alinhamento" torna possível o entendimento das ações em referência aos princípios, valores, objetivos, metas, convergindo com as necessidades e demandas da organização com impacto nos resultados pelas estratégias. Esse item identifica a média das áreas em 20,37 de grau de maturidade, onde o destaque ocorre pelo baixo grau da área da habitação, e a permanência no grau alto, não excedendo acima de 28,3, em que apenas as áreas da assistência social e o esporte e lazer atingiram esse grau na organização. Faz-se necessário alinhar as estratégias, não só para os grupos que exercem o gerenciamento com as lideranças na organização, mas para as equipes, objetivando o resultado proposto junto à comunidade e não no âmbito apenas de gestão interna, visando resultados entre o planejamento e a execução das ações na organização. Essa capacidade de aferição colhe os frutos das ações realizadas.

A dimensão "métricas e monitoramento" auxilia os processos estratégicos de avaliação, enviando informações fundamentais para o processo de trabalho alinhado à preocupação com o atingimento dos resultados, com qualidade, eficiência e efetividade. São utilizados recursos tecnológicos por meio da identificação de dados e informações para reaplicar análises de desempenho, ampliando, assim, a eficácia na habilidade de gerenciar. Identifica-se uma disparidade entre cada área disponível que dá base ao processo de mensuração, o que demonstra o quão engessado se encontra esse mecanismo, pois apenas $20 \%$ das áreas, a assistência social e o abastecimento, possuem grau muito alto. Assim como $20 \%$ concentram seu resultado no grau baixo, levando a média entre as áreas o grau de 20,68 de maturidade. Esse é um ponto fundamental de aferição, traz indicadores, acompanhamento, pontua a necessidade de atenção e avalia os processos da organização. Identifica uma iniciativa e também a preocupação de aferir apenas algumas poucas ações que são prioritárias e de importância para a gestão realizar a mensuração; as demais, em sua grande maioria, se perdem na rotina ou se encontram no domínio apenas de equipes e setores, não estabelecidas como procedimento comum de gestão.

O elemento "processos" culmina na importância de um planejamento que reverte em procedimentos de trabalho organizados para aludir estrategicamente do começo ao fim à execução do proposto pela organização, conforme o gráfico 2 . 
Gráfico 2

\section{Grau de maturidade no elemento processos}

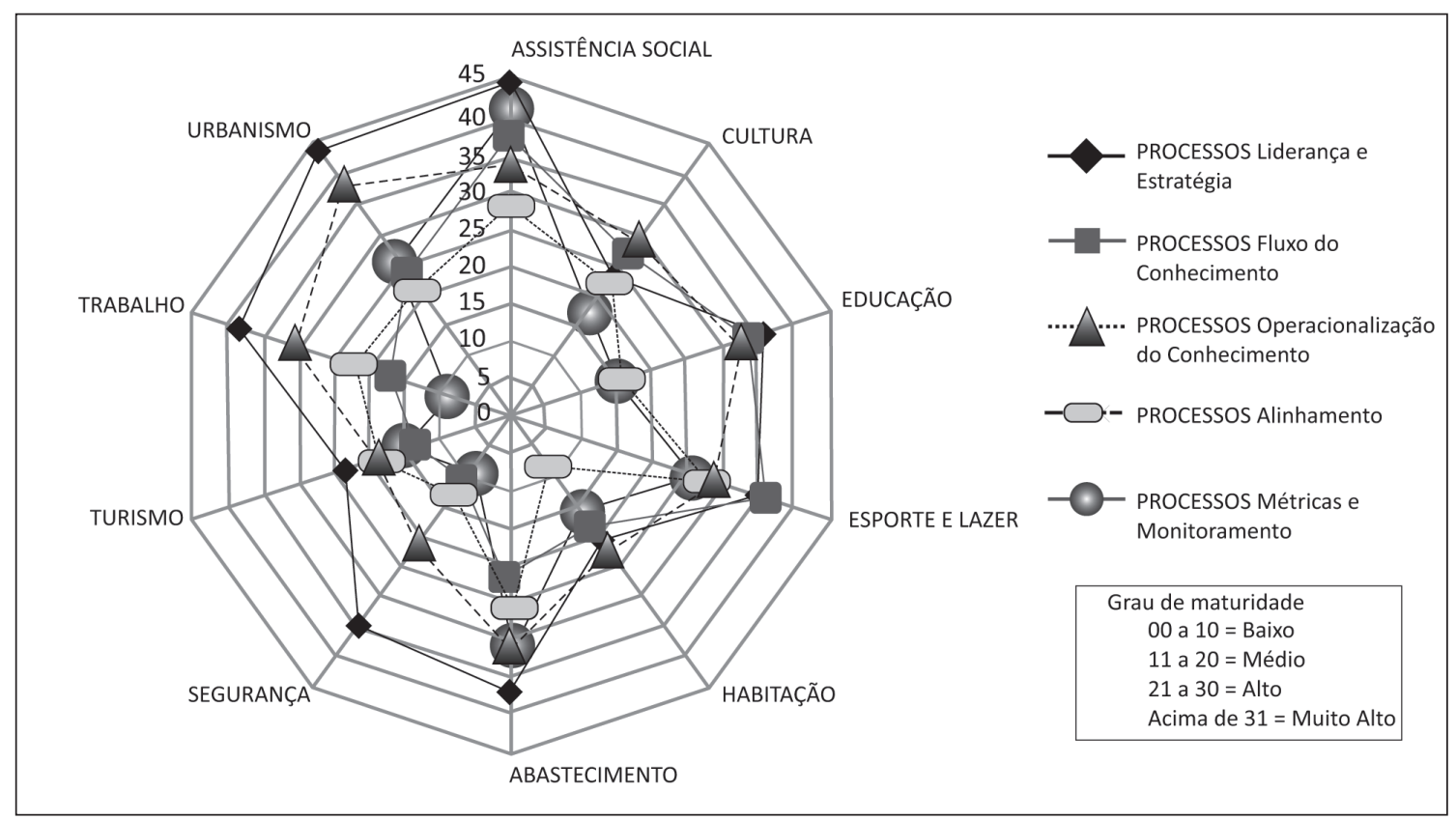

Fonte: Elaborado pelos autores (2013).

Nesse elemento, 65\% das áreas pesquisadas encontram-se concentradas até o grau de maturidade 30, considerado alto por essa aferição. Nesse gráfico, sobrepondo as dimensões do conhecimento em relação às áreas pesquisadas, que, diferentemente do elemento pessoas, ampliam a distância com o grau baixo, expandindo-se para os graus médio e alto. Assim, demonstra que as dimensões do conhecimento alinhamento, métricas e monitoramento necessitam de maior prioridade e intervenção, pois são fundamentais.

— Elemento sistemas: aborda quatro dimensões do conhecimento, são elas: a) tecnologia; b) programa de gestão do conhecimento; c) conteúdo do conhecimento; d) infraestrutura de acesso ao conhecimento, de acordo com a tabela 3.

A dimensão do conhecimento "tecnologia" possibilita maior compreensão do uso de dados e informações, gerando facilidade de conexão, acesso e interação com o sistema. É um recurso que agiliza fluxos e subsidia suporte aos elementos pessoas e processos, permitindo o compartilhamento para o alcance de resultados no ambiente organizacional. Identifica-se a média mais baixa de todas as 14 dimensões apresentadas neste estudo, tanto a média das 10 áreas, totalizando 14,93, quanto não excedendo ao grau 20,1 de maturidade, considerado médio. Isso indica o investimento não só em recursos tecnológicos, como equipamentos, mas a priorização de infraestrutura de suporte para que a comunicação e o acesso aos conhecimentos produzidos sejam organizados e apoiados pelo nível estratégico de gestores aliados às diretrizes de comunicação na organização. Preocupa a distância que duas áreas, justamente 
de pequeno porte, têm em relação às outras, mas também reporta-se às áreas com maior disponibilidade de recurso que não ascenderam ao grau de maturidade, permanecendo no grau médio. Portanto, deve-se priorizar atenção quanto ao uso da tecnologia como instrumento para a inovação na gestão pública.

Tabela 3

Grau de maturidade no elemento sistemas

\begin{tabular}{|lcccc|}
\hline $\begin{array}{l}\text { Áreas de Atuação } \\
\text { da PMC }\end{array}$ & Tecnologia & $\begin{array}{c}\text { Programa de Gestão do } \\
\text { Conhecimento }\end{array}$ & $\begin{array}{c}\text { Conteúdo do } \\
\text { Conhecimento }\end{array}$ & $\begin{array}{c}\text { Infraestrutura de Acesso ao } \\
\text { Conhecimento }\end{array}$ \\
\hline Assistência Social & 19,3 & 34,9 & 40 & 46,9 \\
Cultura & 12,8 & 30 & 28,1 & 39,4 \\
Educação & 14,3 & 26,3 & 38,5 & 44,4 \\
Esporte e Lazer & 14,7 & 29,1 & 37,2 & 45 \\
Habitação & 19,9 & 8,6 & 30,1 & 40,6 \\
Abastecimento & 14,1 & 38,6 & 35 & 39,7 \\
Segurança & 16,7 & 23,7 & 22,1 & 25,3 \\
Turismo & 6,8 & 28,6 & 24,4 & 38,8 \\
Trabalho & 10,6 & 28,6 & 26,4 & 46,3 \\
Urbanismo & 20,1 & 33,4 & 29 & 47,5 \\
Média das 10 áreas & 14,93 & 28,18 & 31,08 & 37,45 \\
\hline
\end{tabular}

Fonte: Elaborado pelos autores (2013).

A dimensão "programa de gestão do conhecimento" subsidia a forma valorativa que a organização tem, tanto em ações formais quanto informais, em face do ambiente criativo, inovador e estratégico da GC, apoiado por pessoas e processos em prol de criar e produzir novos conhecimentos na organização. Os resultados percebidos denotam desde um grau baixo até muito alto, apresentando uma diferença de 30 pontos no grau de maturidade entre uma área e outra, mesmo concentrados no porte médio de organizações. Traduz-se que essa diretriz pode ser única, mas o impacto deve ser revisto. Apresenta áreas bem valorizadas em $60 \%$ com grau alto, 30\% muito alto e 10\% baixo, demonstrando que o programa de gestão do conhecimento está muito mais voltado aos recursos, a partir de ações que geram produtos e práticas operacionais. A média considerada de grau de maturidade alto propicia 70\% das áreas acima.

Essa dimensão se refere ao "conteúdo do conhecimento", identifica as ferramentas, instrumentos e meios para gerenciar as informações e dados sobre as necessidades, lacunas, demandas, tanto das pessoas quanto daquilo que a organização necessita estimular com o repasse de compreensão do significado para o desenvolvimento de novos conhecimentos na organização. Aprofunda a aferição sobre a forma como as pessoas geram conhecimento, compondo $40 \%$ com grau de maturidade muito alto e 60\% com grau alto. Destaca-se a expressão da qualidade dos conteúdos organizados e utilizados nas capacitações e no aperfeiçoamento, 
produzindo maior interação entre pessoas e processos, reforçando a importância da organização em ter um órgão que fomenta a formação e dá sustentação técnica para as pessoas desempenharem suas funções e atribuições.

A dimensão "infraestrutura de acesso ao conhecimento" se refere à organização de estrutura para acesso e compartilhamento do conhecimento dos líderes, gestores, grupos que atuam na organização; quais sistemas, enquanto recursos tecnológicos, são acessíveis para impulsionar a criação e a produção. A interação com meios físicos e sistematizados, mecanismos esses que potencializam a geração de metodologias, facilita a apropriação e a compreensão do conhecimento, mediando o uso estratégico para atingir resultados. Nesse item, reflete a geração de estrutura possibilitando o acesso à comunicação e à informação; e consequentemente a apropriação de conteúdo, a interpretação, o conhecimento produzido.

Fechando, temos o elemento "sistemas". Percebe-se que a média das áreas representa um significativo avanço, tendo em vista o alcance do veículo tecnológico, por meio de sistemas, possibilitando o trânsito entre pessoas para que o conhecimento seja produzido na organização. No gráfico 3 identifica-se a sobreposição das dimensões do conhecimento em relação ao elemento sistemas.

Gráfico 3

Grau de maturidade no elemento sistemas

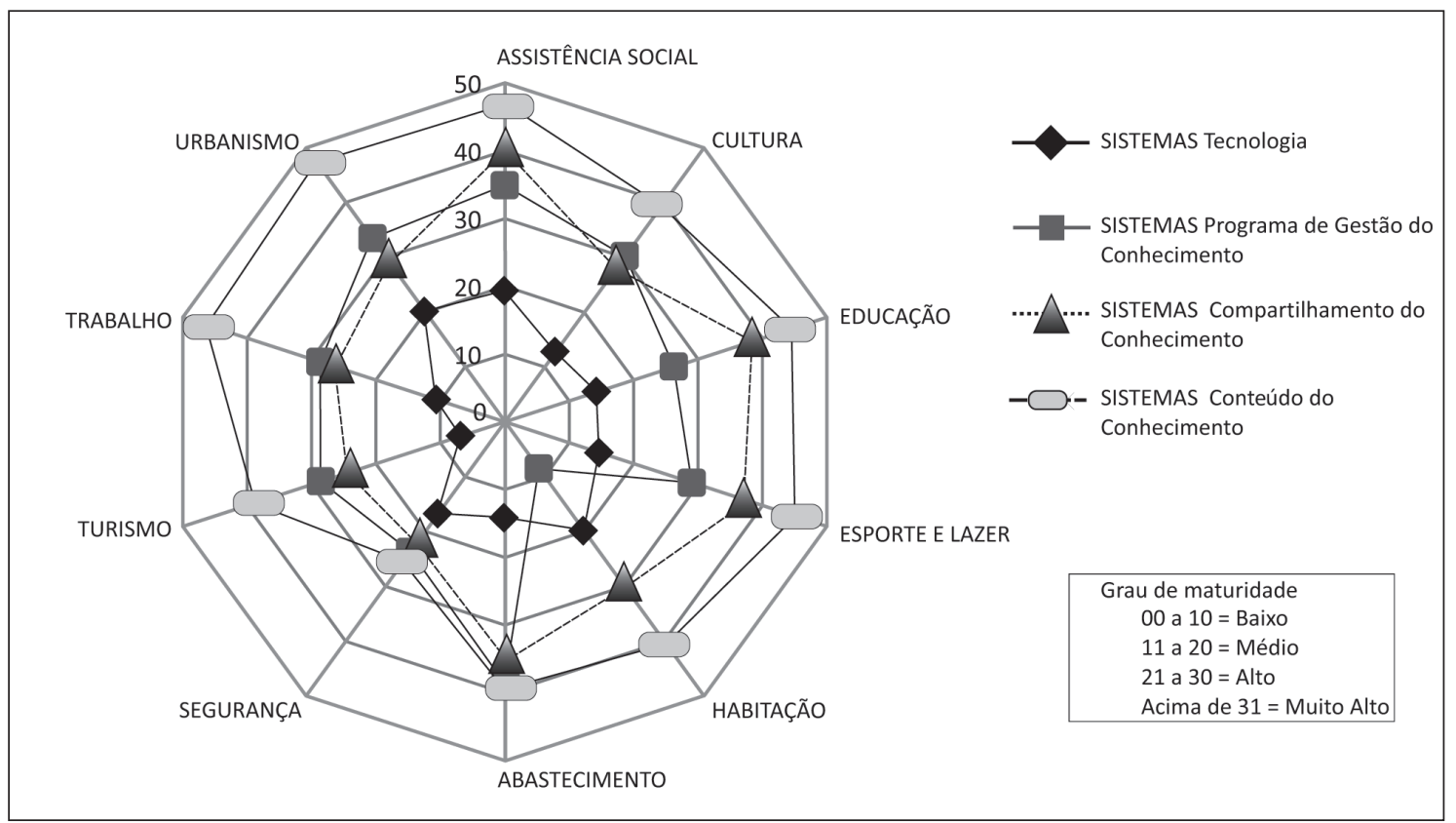

Fonte: Elaborado pelos autores (2013).

No gráfico acima se identifica que o item tecnologia mostrou-se o mais baixo vinculado tanto a este elemento sistemas quanto ao das 14 dimensões do conhecimento, como também, 
em contraponto, o item infraestrutura de acesso ao conhecimento mostrou a média mais alta dessas dimensões, ambos componentes do elemento sistemas. Visualmente apresenta um destaque qualitativo ante as ações que identificam os produtos e práticas geradas pelo Programa de Gestão do Conhecimento na Prefeitura, pois o elemento sistemas concentra em síntese a resultante dos elementos anteriores.

\section{Considerações finais}

O método OKA escolhido como ferramenta/base deste estudo de caso para se identificar o grau de maturidade da GC apresenta um aspecto que é necessário avaliar: a sua funcionalidade. O método responde de forma objetiva ao grau identificado no resultado apresentado, permite ter clareza em que ponto se está e onde se quer chegar, e como a organização se apresenta; oferece, também, um resultado de pontuação que remete ao foco e à revisão de estratégias para a implantação e implementação de ações focadas no controle dos processos e de avaliação dos mesmos na organização. Assim, reforça a importância da GC como um componente fundamental para a construção do planejamento e da gestão estratégica municipal, tanto por reunir processos e fluxos de trabalho, ordenados e organizados de forma integrada e interativa, quanto por propiciar a geração e a produção de novos conhecimentos.

Referente às etapas e fases previstas para a execução do Método OKA, três pontos ressaltam foco, são eles: a aprovação da alta administração ou gerência, corroborando com o alinhamento estratégico da organização; a capacitação dos participantes potencializando as informações e a identificação do conhecimento produzido na organização; e a análise dos resultados, com foco em oficinas de trabalho propiciando discussões, encaminhamentos e avaliação do processo. Segundo Fresneda e Gonçalves (2007:13), o método apresenta um "conjunto amplo de informações que possibilitam a elaboração do Plano de Gestão do Conhecimento alinhado à estratégia e aos objetivos da organização".

No tocante a escala métrica aferida por Fonseca (2006), os resultados apresentados com o grau de maturidade propiciam uma leitura numérica, que atribui grau baixo de 0 a 10 , grau médio de 11 a 20 , grau alto de 21 a 30, e grau muito alto acima de 31 . Na aplicação dessa aferição na PMC, apresenta-se uma revisão, lançando uma nova distribuição na escala quali-quantitativa com o grau de maturidade muito baixo de 0 a 10, grau baixo de 11 a 20 , grau médio de 21 a 30, grau alto de 31 a 40, e grau muito alto acima de 41. Assim, atingindo um nível de exigência maior pela aferição que pontua até o grau 59; concentrando o grau de maturidade alto apenas para a pontuação acima de 31, considerada maior que 50\%. Essa revisão da aferição visa ampliar o critério de análise qualitativo diante do significado quantitativo, estabelecendo índices que representam o impacto na gestão, contribuindo prioritariamente para as ações de planejamento e de gestão alinhadas à missão, à visão e aos valores da orga- 
nização, requerendo um espaço estratégico na estrutura organizacional, visando o impacto qualitativo em seus resultados.

Do ponto de vista do sistema aplicado, o SysOKA apresenta três elementos: pessoas, processos e sistemas; evidencia-se que esses itens possuem delimitações muito tênues entre as dimensões do conhecimento atribuídas aos elementos, apresentando um trânsito entre elas, fato que dificulta sua compreensão. O questionário aplicado demonstrou que se optou por seguir uma lógica sequencial exploratória a partir da composição de cada uma das dimensões do conhecimento alinhadas para cada elemento, mas as perguntas que contemplam as dimensões devem ser realinhadas para uma melhor aproximação sobre a coleta de dados e informações referente aos pontos, não sendo dúbias suas interpretações; assim como a revisão do texto em face da linguagem da administração pública.

Quanto à identificação da gestão do conhecimento no setor público, esta se manifesta a partir de referenciais da administração privada, se apropriando e adequando a linguagem competitiva produtiva para o alcance dos fins; porém na organização pública devem fazer parte apenas os conceitos de gestão de processos de trabalho e de burocracia. Assim, com formato estratégico de gerenciamento para resultados, questiona-se sobre essa contradição, pois a gestão para resultados é um modelo que assume e agrega valor de gerenciamento à PMC, pois foca essencialmente planejamento estratégico, monitoramento e avaliação das ações pactuadas com o nível de atingimento de suas metas e de seus indicadores. Mas apresenta fragilidade no que diz respeito ao impacto, pois uma minoria de ações, projetos ou programas é pactuada e acordada com as demais ações que permeiam os processos e que acabam por não fazer parte desse gerenciamento. Como não são prioritárias, se perdem e encontram-se solitárias, sem o rigor de uma diretriz de governo aliada a políticas públicas e políticas internas de estrutura e funcionamento. Acrescenta-se que, por estarem programadas e incluídas em planos anuais, planos diretores, leis, decretos, diretrizes orçamentárias e outros, ainda têm por finalidade o cumprimento de ações, projetos, programas com resposta de diálogo com a comunidade e para a comunidade, o cidadão. Não desmerecendo a qualidade dos serviços prestados à população, mas discutindo o alinhamento entre as ações e o impacto para servidores e para a comunidade da cidade de Curitiba.

Assim, ações da gestão do conhecimento foram timidamente respondidas como parte qualitativa da gestão por resultados, como fruto de um plano de governo agindo sobre a política pública alinhado estrategicamente, focando a gestão interna de processos, apropriandose de dados quantitativos e de resultados alcançados, mas não das pessoas que nela atuam. Apresenta-se a administração pública municipal como uma concorrência com ela própria, entre áreas e setores, sempre em vias de superar o estado anterior, consequentemente desalinhado com o ponto de vista da produção de novos conhecimentos, gerando novos obstáculos a suprir, a ultrapassar. E como parte qualitativa, por provocar pessoas e equipes que respondem a suas atribuições num pensar criativo, inovador diante dos desafios.

Com este estudo, percebe-se a que gestão do conhecimento, ou mais propriamente a gestão estratégica de processo de trabalho para a produção do conhecimento, deve permear 
todos os ambientes do setor público, como facilitador e promotor de processos e sistemas que propiciam a participação de pessoas da organização, e da rede de relacionamento (instituições de ensino, empresas terceirizadas e outros entes privados e públicos), em prol da realização, por meio do acesso ao fomento e ao compartilhamento do conhecimento, de pessoas e equipes de trabalho, a fim de rever ações, projetos, programas, planos, modelos que contribuam para o planejamento e para a gestão no setor público.

Assim, a gestão do conhecimento pode ser vista como um conjunto de processos que orientam a criação, disseminação e utilização do conhecimento para atingir os objetivos da organização (Davenport e Prusak, 1998). Mostra-se também o quão importante é, para a estrutura da gestão pública de Curitiba, uma instância que promove o fomento e o aperfeiçoamento de servidores públicos municipais e o desenvolvimento institucional em prol do encontro com o compromisso do estado com as políticas públicas voltadas às necessidades e demandas da comunidade/população: o Instituto Municipal de Administração Pública (Imap).

Na gestão pública de Curitiba, que utilizou até 2012 o modelo de gestão por resultados, verificou-se que se optou por focar sua gestão para o ambiente interno de avaliação com acentuado posicionamento na gestão de processos, sistemas, fluxos, organogramas, deixando de fora as prioridades que são o foco nas demandas da comunidade com o baixo impacto nas políticas públicas, pensando os cidadãos como pessoas de direitos e não apenas como contribuintes, como clientes. Tem-se, como papel e função pública, de atingir o social, resolver problemas da cidade sim, mas em atenção aos cidadãos; dar-lhes condição de exercer direitos de acesso e principalmente de garantir espaço de participação na construção das políticas públicas.

\section{Referências}

ANGELONI, Maria T. (Org.). Organizações do conhecimento: infraestrutura, pessoas e tecnologia. São Paulo: Saraiva, 2008.

BANCO MUNDIAL. O relatório do desenvolvimento mundial 1998/1999: conhecimento para o desenvolvimento. Brasília: 1999.

BATISTA, Fábio et al. Gestão do conhecimento na administração pública. Brasília: Ipea, 2005.

BOBBIO, Norberto; BOVERO, Michelangelo. Sociedade e Estado na filosofia política moderna. 4. ed. São Paulo: Brasiliense, 1994.

BRASIL. Escola Nacional de Administração Pública - ENAP. Disponível em: <www.enap.gov. br/index.php? searchword=diagnosticando\&option $=$ com_search\&Itemid $=>$. Acesso em: $15 \mathrm{dez}$. 2012a. 
BRASIL. Ministério de Planejamento, Orçamento e Gestão — MPOG. 2012b. Disponível em: <www. governoeletronico.gov.br/o-gov.br/comites-tecnicos/gestao-do-conhecimento-e-informacao-estrategica >. Acesso em: 12. nov 2012b.

CURITIBA. Instituto Municipal de Administração Pública. Disponível em: <www.imap.curitiba. pr.gov.br/index.php?option $=$ com_docman\&task $=$ cat_view\&gid $=204 \&$ limit $=20 \&$ limitstart $=0 \&$ o rder $=$ name\&dir $=$ ASC\&Itemid $=90>$. Acesso em: 15 jul. 2012.

DAVENPORT, Thomas H.; PRUSAK, Laurence. Conhecimento empresarial: como as organizações gerenciam o seu capital intelectual. 2. ed. Rio de Janeiro: Campus, 1998.

DE LONG, David; DAVENPORT, Thomas; BEERS, Mike. What is knowledge management projectresearch. Note. Austin: Texas University, 1997.

DRUCKER, Peter. Desafios gerenciais para o século XXI. São Paulo: Pioneira, 1999.

FIDELIS, Jussara; REZENDE, Denis A. Contribuições estratégicas do planejamento na gestão municipal: um estudo de caso. RIC - Revista de Informação Contábil, v. 2, n. 2, p. 122-140, abr./jun. 2008.

FONSECA, Ana F. Organizational knowledge assessment methodology. Washington: World Bank Institute, 2006.

FRESNEDA, Paulo S.; GONÇALVES Sonia M. A experiência brasileira na formulação de uma proposta de política de gestão do conhecimento para administração pública federal. Brasília: Centro de Documentação e Informação, Coordenação de Publicações, 2007.

GIACOMINI, Carlos H. (Org.). Gestão para resultados em Curitiba: a experiência de contratualização. Curitiba: Imap, 2009.

MATIAS-PEREIRA, José. Curso de administração pública: com foco nas instituições e ações governamentais. 3. ed. São Paulo: Atlas, 2010.

NONAKA, Ikujiro; TAKEUCHI, Hirotaka. The knowledge-creating company: how the dynamics of innovation. Nova York: Oxford University Press, 1995.

PELUFFO, Martha B.; CATALAN CONTRERAS, Edith. Introducción a la gestión del conocimiento y su aplicación al sector público. Santiago de Chile: Cepal; Eclac, 2002.

POLANYI, Michael. The tacit dimension. In: PRUSAK, Laurence (Org.). Knowledge in organizations. Boston: Butteworth Heinemann, 1996.

PRESTES MOTTA, Fernando C. Gestão contemporânea: a ciência e a arte de ser dirigente. 8. ed. Rio de Janeiro: Record, 1997.

SANTOS, Antonio R. et al. Gestão do conhecimento: uma experiência para o sucesso empresarial. Curitiba: Champagnat, 2001.

SERRA, Alberto. Modelo aberto de gestão para resultados no setor público. Natal: Searh/RN, 2008. 
SVEIBY, Karl E. A nova riqueza das organizações: gerenciando e avaliando patrimônio de conhecimento. Rio de Janeiro: Campus, 1998.

TERRA, José C. C. Gestão do conhecimento: o grande desafio empresarial. Rio de Janeiro: Elseveier, 2005.

WALDO, Dwight. O estudo da administração pública. 2. ed. Rio de Janeiro: Fundação Getulio Vargas, 1971.

WILSON, Woodrow. O estudo da administração. Revista do Serviço Público, v. 3, n. 56, p. 349-366, jul./set. 2005.

Carla Cristine Braun é mestre em organizações e desenvolvimento, assistente social, pedagoga, docente do Banco de Colaboradores da Escola de Administração Pública (EAP), servidora pública do Instituto Municipal de Administração Pública (Imap) em Curitiba. E-mail: cbraun@imap.curitiba.pr.gov.br.

Rafael Rodrigo Mueller é doutor em educação, professor adjunto do Programa de Pós-Graduação em Desenvolvimento Socioeconômico da Universidade do Extremo Sul Catarinense (Unesc). E-mail: rrmueller@ymail.com. 